\title{
Triptolide interrupts rRNA synthesis and induces the RPL23-MDM2-p53 pathway to repress lung cancer cells
}

\author{
JUAN WANG $^{1 *}$, ZHI-QIAN ZHANG ${ }^{2 *}$, FANG-QIONG LI ${ }^{1}$, JIA-NING CHEN ${ }^{3}$, \\ XIAOTING GONG ${ }^{1}$, BEI-BEI CAO ${ }^{4}$ and WEI WANG ${ }^{1}$
}

\author{
${ }^{1}$ Department of Clinical Laboratory, Tongde Hospital of Zhejiang Province, Hangzhou, Zhejiang 310012; \\ ${ }^{2}$ College of Medical Technology, Zhejiang Chinese Medical University, Hangzhou, Zhejiang 310053; \\ ${ }^{3}$ State Key Laboratory for Diagnosis and Treatment of Infectious Diseases, Collaborative Innovation Center for \\ Diagnosis and Treatment of Infectious Diseases, The First Affiliated Hospital, College of Medicine, \\ Zhejiang University, Hangzhou, Zhejiang 310003; ${ }^{4}$ Department of Clinical Laboratory, \\ Hangzhou Linan District People's Hospital, Hangzhou, Zhejiang 311300, P.R. China
}

Received November 5, 2019; Accepted March 9, 2020

DOI: $10.3892 /$ or.2020.7569

\begin{abstract}
Lung cancer has one of the highest mortalities of any cancer worldwide. Triptolide (TP) is a promising tumor suppressor extracted from the Chinese herb Tripterygium wilfordii. Our previous proteomics analysis revealed that TP significantly interfered with the ribosome biogenesis pathway; however, the underlying molecular mechanism remains poorly understood. The aim of the present study was to determine the molecular mechanism of TP's anticancer effect by investigating the association between ribosomal stress and p53 activation. It was found that TP induces nucleolar disintegration together with RNA polymerase I (Pol I) and upstream binding factor (UBF) translocation. TP interrupted ribosomal (r)RNA synthesis through inhibition of RNA Pol I and UBF transcriptional activation. TP treatment increased the binding of ribosomal protein L23 (RPL23) to mouse double minute 2 protein (MDM2), resulting in p53 being released from MDM2 and stabilized. Activation of p53 induced apoptosis and cell cycle arrest by enhancing the activation of p53 upregulated modulator of apoptosis, caspase 9 and caspase 3, and suppressing BCL2. In vivo experiments showed that TP significantly reduced xenograft tumor size and increased mouse body weight. Immunohistochemical assays confirmed that TP significantly increased the p53 level and induced nucleolus disintegration, during which nucleolin
\end{abstract}

Correspondence to: Professor Wei Wang, Department of Clinical Laboratory, Tongde Hospital of Zhejiang Province, 234 Gucui Road, Hangzhou, Zhejiang 310012, P.R. China

E-mail: wangweihz8@163.com

${ }^{*}$ Contributed equally

Key words: triptolide, ribosome, mouse double minute 2, p53, ribosomal protein L23 distribution moved from the nucleolus to the nucleoplasm, and RPL23 clustered at the edge of the cell membrane. Therefore, it was proposed that TP induces ribosomal stress, which leads to nucleolus disintegration, and inhibition of rRNA transcription and synthesis, resulting in increased binding of RPL23 with MDM2. Consequently, p53 is activated, which induces apoptosis and cell cycle arrest.

\section{Introduction}

According to statistics from the World Health Organization, the mortality of lung cancer in 2018 was $\sim 1.8$ million worldwide, accounting for $18.4 \%$ of total cancer deaths (1), resulting in lung cancer being one of the deadliest malignant tumors worldwide. Non-small cell lung cancer (NSCLC) accounts for $\sim 80 \%$ of deaths from lung cancer (2). In NSCLC cells, the mechanism of cell death regulation is seriously unbalanced, leading to uncontrolled cancer cell proliferation (3). Therefore, inducing cancer cell death is the primary focus of clinical lung cancer treatment (4). Currently, the side effects and toxicity of chemotherapy and radiotherapy have created a bottleneck in clinical curative treatments (5). Therefore, there is an urgent need to discover alternative reagents or novel strategies to treat lung cancer.

Tripterygium wilfordii Hook $\mathrm{F}$ is a promising antitumor Chinese herb with the ability to regulate disease by promoting blood circulation, improving blood stasis and detoxifying harmful metabolites (6). Triptolide (TP), a lactone compound with a unique diterpene and triperoxide structural form, is the major biologically active component extracted from the root, stem, rhizome and leaf of Tripterygium wilfordii Hook $F(7)$. TP has previously been applied to treat rheumatoid arthritis and nephritis due to its immunosuppressive and anti-inflammatory actions (8). Recently, studies have revealed that TP effectively represses the growth of multiple tumor cells by inhibiting cell proliferation, and inducing apoptosis both in vivo and in vitro (9). The heterogeneity of tumors in different organs makes it necessary to explore the unique mechanisms 
of specific tumors for targeted therapy. Our previous results showed that TP inhibits NSCLC cells by blocking the cell cycle and inducing apoptosis (10), and an isobaric tags for relative and absolute quantitation-based proteomics analysis revealed that the ribosome biogenesis pathway was significantly altered in TP-treated NSCLC cells (11).

Ribosome biogenesis has attracted increasing attention in molecular research over the past decade due to its beneficial role in controlling the translation of all proteins in the cell, and thus governing cell growth and proliferation. The nucleolus, a subnuclear unit of the nucleus, contains ribosomal (r)DNA genes, which are transcribed by RNA polymerase I (Pol I), resulting in a single transcript known as 47S pre-rRNA (12). 47S-pre-rRNA is initially processed into $45 \mathrm{~S}$ rRNA and further spliced into 18S rRNA (13). The upstream binding factor (UBF), together with RNA Pol I, constitutes an important component of the pre-initiation complex that participates in the initiation of ribosome biogenesis (14). UBF binds to the whole length of the rDNA transcript units and is implicated in the control of the elongation process (15). When cells are subjected to stress, the nucleolus acts as a sensor for cellular stress signals, resulting in the recruitment of ribosomal proteins (RPs) to mouse double minute 2 protein (MDM2), thereby disrupting the interaction between p53 and MDM2 (16). As a result, p53 is no longer degraded by MDM2-mediated ubiquitination, which further induces cell cycle arrest or apoptosis (16). In addition, TP inhibits the activity of RNA Pol I (17), suggesting that TP may be involved in regulating ribosome biogenesis. However, the underlying mechanism remains unclear. Thus, it was hypothesized that perturbation of ribosome biogenesis may be related to TP-induced apoptosis in NSCLC cells. The aim of the present study was to determine the effect of TP on ribosome biogenesis in A549 cells, and reveal the molecular mechanisms mediating TP-induced apoptosis and cell cycle arrest for improved utilization of TP in lung cancer therapy.

\section{Materials and methods}

Cell culture. Human lung cancer A549 cells (cat. no.CCL-185 ${ }^{\mathrm{TM}}$; American Type Culture Collection) were cultured at $37^{\circ} \mathrm{C}$ in a humidified atmosphere with $5 \% \mathrm{CO}_{2}$ in Dulbecco's modified Eagle's medium (DMEM; Gibco; Thermo Fisher Scientific, Inc.) supplemented with $10 \%$ FBS (Thermo Fisher Scientific, Inc.) and $1 \%$ penicillin-streptomycin (Thermo Fisher Scientific, Inc.). The cell line was authenticated using short tandem repeat profiling and mycoplasmas were tested to confirm that the cells were free of contamination.

Chemicals. TP ( $\geq 98 \%$ ) and actinomycin D (Act D, $20 \mathrm{ng} / \mathrm{ml}$ ) were obtained from Sigma-Aldrich (Merck KGaA). These drugs were aliquoted upon delivery, stored at $100 \mu \mathrm{g} / \mathrm{ml}$ in DMSO at $-80^{\circ} \mathrm{C}$, and diluted to the indicated concentrations using serum-free culture medium when used. Cells were treated with Act D for $36 \mathrm{~h}$ prior to relevant experiments.

Cell cycle, apoptosis and proliferation. Cells were treated with $\mathrm{TP}$ at $12.5,50$ and $100 \mathrm{ng} / \mathrm{ml}$ for $36 \mathrm{~h}$. Apoptosis, cell cycle and cell viability were detected according to the manufacturer's instructions. For apoptosis, $5 \times 10^{5}$ cells were collected with EDTA-free trypsin, washed with cold PBS, incubated with $5 \mu 1$ Annexin V-FITC and $10 \mu$ propidium iodide (PI; $20 \mu \mathrm{g} / \mathrm{ml}$ ) at room temperature for $15 \mathrm{~min}$ in the dark, and analyzed by a FACS Canto II instrument (BD Biosciences); the apoptotic rate was calculated as the sum of early + late apoptotic cells.

For cell cycle analysis, $5 \times 10^{5}$ cells were fixed with absolute ethanol at $-20^{\circ} \mathrm{C}$ overnight, washed with cold PBS, incubated with $5 \mathrm{mg} / \mathrm{ml} \mathrm{RNase}$ at $37^{\circ} \mathrm{C}$ for $30 \mathrm{~min}$, stained with $5 \mathrm{mg} / \mathrm{ml}$ $\mathrm{PI}$ in the dark at room temperature for $30 \mathrm{~min}$, and last analyzed by a FACS Canto II. Flow cytometry data were analyzed with FlowJo 7.6 software (FlowJo LLC).

For cell viability, $3 \times 10^{3}$ cells were seeded in 96-well plates and cultured with $100 \mu 1$ DMEM. Cell Counting Kit-8 solution (Dojindo Molecular Technologies, Inc.) was incubated with cells at $37^{\circ} \mathrm{C}$ for $3 \mathrm{~h}$. Absorbance at $450 \mathrm{~nm}$ was measured, and cell viability was evaluated according to the manufacturer's instructions.

Reverse transcription-quantitative PCR (RT-qPCR). TRIzol ${ }^{\circledR}$ reagent (Invitrogen; Thermo Fisher Scientific, Inc.) was used to extract total cellular RNA. RT was conducted using a PrimeScript RT reagent kit (Takara Bio, Inc.) according to the manufacturer's instructions. Amplification of 45S and 18S rRNA was performed using a C1000 Thermal Cycler detection system (Bio-Rad Laboratories, Inc.) in triplicate using $1 \mathrm{ng}$ of cDNA, $125 \mathrm{nM}$ forward and reverse primer and $25 \mu \mathrm{l} 2 \mathrm{X} \mathrm{SYBR}^{\circledR}$ Premix Ex Taq ${ }^{\mathrm{TM}}$ (Takara Bio, Inc.) in a 50- $\mu 1$ reaction. The reaction parameters were $95^{\circ} \mathrm{C}$ for $1 \mathrm{~min}$, followed by 42 cycles of $95^{\circ} \mathrm{C}$ for $15 \mathrm{sec}$, $56^{\circ} \mathrm{C}$ for $25 \mathrm{sec}$ and $72^{\circ} \mathrm{C}$ for $30 \mathrm{sec}$. The following primers were used: $45 \mathrm{~S}$ forward, 5'-GCGGAACCCTCGCTT CTC-3' and reverse, 5'-CTCCGTTATGGTAGCGCTGC-3'; $18 \mathrm{~S}$ forward, 5'-CTCTCCGGAATCGAACCCTGA-3' and reverse, 5'-CGACGACCCATTCGAACGTCT-3'; and GAPDH forward, 5'-AGCCACATCGCTCAGAACAC-3' and reverse, 5'-GAGGCATTGCTGATGATCTTG-3'. The relative mRNA expression levels were quantified using the $2^{-\Delta \Delta \mathrm{Cq}}$ method (18); GAPDH was used as the internal reference.

Immunoprecipitation(IP) assay. Cells were washed and scraped with cold PBS, centrifuged at $16,000 \mathrm{x}$ g at $4^{\circ} \mathrm{C}$ for $15 \mathrm{~min}$, and suspended in IP lysis buffer (Cell Signaling Technology, Inc.). Protein concentrations were measured using a bicinchoninic acid (BCA) protein assay kit (Thermo Fisher Scientific, Inc.). Protein $(100 \mu \mathrm{g})$ was incubated with anti-MDM2 (1:100; cat. no. 86934; Cell Signaling Technology, Inc.) or IgG (1:500; cat. no. sc-2025; Santa Cruz Biotechnology, Inc.) antibodies mixed with $500 \mu \mathrm{l}$ of TBS- $0.5 \%$ Tween 20 (TBST) along with $10 \mu \mathrm{l}$ of Dynabeads protein $\mathrm{G}$ on a rotating platform at $4^{\circ} \mathrm{C}$ overnight. Protein beads were then washed three times with $0.6 \mathrm{ml}$ of ice-cold TBST buffer. A micropipette was used to remove the last traces of buffer. Antibody-protein complexes were eluted with $1 \mathrm{X}$ SDS sample buffer, electrophoresed and subjected to western blotting.

Western blot analysis. TP-treated cells were collected with Cell Lysis Buffer (cat. no. 9803S; Cell Signaling Technology, Inc.) supplemented with phenylmethanesulfonylfluoride fluoride (cat. no. 8553S; Cell Signaling Technology, Inc.) at the indicated times. The BCA assay kit was used to determine 
the protein concentrations. Proteins $(30 \mu \mathrm{g})$ were denatured in boiling water for $10 \mathrm{~min}$ and fractioned by using SDS-PAGE with $10 \%$ denaturing acrylamide gels. The fractioned proteins were transferred to polyvinylidene fluoride membranes. The blotted membranes were blocked with $5 \%$ nonfat milk in TBST for $1 \mathrm{~h}$ at room temperature, followed by incubation with the diluted primary antibodies against MDM2 (1:1,000; cat. no. 86934, Cell Signaling Technology, Inc), phosphorylated (p)-p53 (1:1,000; cat. no. 2521; Cell Signaling Technology, Inc), cleaved (c)-caspase 9 (1:1,000; cat. no. 20750; Cell Signaling Technology, Inc), c-caspase 3 (1:1,000; cat. no. 9664; Cell Signaling Technology, Inc), GAPDH (1:1,000; cat. no. 5174; Cell Signaling Technology, Inc.), RPL23 (1:3,000, cat. no. ab241088; Abcam), p53 (1:5,000; cat. no. 10442-1-AP; ProteinTech Group, Inc.), p53 upregulated modulator of apoptosis (1:1,000; PUMA; cat. no. 55120-1-AP; ProteinTech Group, Inc.) and BCL2 (1:1,000; cat. no. 12789-1-AP; ProteinTech Group, Inc.) at $4^{\circ} \mathrm{C}$ for overnight. The membranes were then incubated with horseradish peroxidase-conjugated secondary antibody (1:2,000; cat. nos. 7076 and 7074; Cell Signaling Technology, Inc.) for $1.5 \mathrm{~h}$ at room temperature. Enhanced chemiluminescence reagents (EMD Millipore) were used to visualize the immunoreactive proteins, and densitometric analysis was performed by using ImageJ v1.8.0 software (National Institutes Of Health).

Immunofluorescence assay. Cells were seeded into confocal microscopy dishes, treated with $50 \mathrm{ng} / \mathrm{ml} \mathrm{TP}$ for $24 \mathrm{~h}$ and fixed in $4 \%$ paraformaldehyde at room temperature for $20 \mathrm{~min}$. Next, $0.2 \%$ Triton $\mathrm{X}-100$ was used to permeabilize the membranes. The prepared cells were washed with cold PBS and blocked with $3 \%$ bovine serum albumin (BSA; Sigma-Aldrich; Merck $\mathrm{KGaA}$ ) at room temperature for $30 \mathrm{~min}$. Primary antibodies against nucleophosmin (B23; 1:200; cat. no. ab15440; Abcam; or 1:100; cat. no. 10306-1-AP; ProteinTech Group, Inc.), RNA Pol I (1:100; cat. no. sc-48385; Santa Cruz Biotechnology, Inc.), UBF (1:100; cat. no. sc-13125; Santa Cruz Biotechnology, Inc.) and nucleolin (NCL; 1:1,000; cat. no. 14574; Cell Signaling Technology, Inc.) were added and incubated at $4^{\circ} \mathrm{C}$ overnight. Dylight ${ }^{\mathrm{TM}} 488$ (green) or 594 (red)-conjugated secondary antibodies (1:500; cat. nos. A23210 and A23420; Abbkine Scientific Co., Ltd.) were applied for $1 \mathrm{~h}$ at room temperature. DAPI (Thermo Fisher Scientific, Inc.) was used to counterstain the nuclei. Immunofluorescent images of the prepared cells were viewed under a fluorescence laserscanning confocal microscope (magnification, x63; Carl Zeiss AG) in 20 randomly selected fields.

Incorporation of 5-fluorouridine (5-FU) into rRNA. Cells were seeded on coverslips and incubated with DMEM for adherence. Then, $50 \mathrm{ng} / \mathrm{ml} \mathrm{TP}$ was used to stimulate the cells for $24 \mathrm{~h}$. Next, 2 mM 5-FU (Sigma-Aldrich; Merck $\mathrm{KGaA}$ ) was incubated with the cells growing on coverslips at room temperature for $15 \mathrm{~min}$. The processes of washing, fixation and membrane permeabilization were performed as described in the Immunofluorescence assay section. Specific monoclonal antibodies recognizing halogenated uridine (1:400; cat. no. B8434; Merck KGaA) and NCL (cat. no. 14574; Cell Signaling Technology, Inc.) were used to incubate with the prepared cells at $4^{\circ} \mathrm{C}$ overnight. Dylight-conjugated secondary antibody incubation, nuclear counterstaining and immunofluorescent imaging were conducted as previously described.

Chromatin IP $($ ChIP) analysis. ChIP assays were performed according to the manufacturer's instructions (EZ ChIP ${ }^{\text {тм }}$ kit; cat. no. 17-371; EMD Millipore). Briefly, the prepared cells were cross-linked with $1 \%$ formaldehyde for $10 \mathrm{~min}$ at room temperature. The unreacted formaldehyde was quenched using $0.125 \mathrm{M}$ glycine. The cells were washed with cooled PBS containing protease inhibitor cocktail II included in the kit for $5 \mathrm{~min}$, and then scraped and pelleted. The cell pellets were lysed in $1 \%$ SDS lysis buffer. Sonication (pulse for $5 \mathrm{sec}$, pause for $9 \mathrm{sec}$, cycle 23 times) on wet ice $\left(0^{\circ} \mathrm{C}\right)$ was conducted for DNA fragmentation. An aliquot of the sheared lysate was preserved at $4^{\circ} \mathrm{C}$ until use as an input control. Sheared lysate (100 $\mu \mathrm{l})$ was diluted with dilution buffer and incubated with anti-UBF (1:50; cat. no. sc-13125; Santa Cruz Biotechnology, Inc.) and anti-RNA Pol I antibodies (1:50; cat. no. sc-48385; Santa Cruz Biotechnology, Inc.) on a rotating rack at $4^{\circ} \mathrm{C}$ for overnight. The immunocomplexes containing DNA, protein and antibodies were captured using protein A-agarose. Immunocomplexes conjugated with beads were eluted using elution buffer including $1 \% \mathrm{SDS}$ and $100 \mathrm{mM} \mathrm{NaHCO}$ and reverse cross-linked at $65^{\circ} \mathrm{C}$ overnight. DNA fragments were collected, and UBF and RNA Pol I enrichment in the rDNA promoter were amplified using RT-qPCR as previously described. The primers for augmenting the rRNA promoter DNA were as follows: Forward, 5'-CGATGGTGGCGTTTT TGG-3' and reverse, 5'-CCGACTCGGAGCGAAAGATA-3'. The negative control comprised the same assay conducted using a human normal IgG antibody (cat. no. sc-2025; Santa Cruz Biotechnology, Inc.

Animal studies. A549 cells $\left(5 \times 10^{6}\right)$ were injected subcutaneously into 10 4-week-old male BALB/cAnNCr-nu/nu nude mice (18-22 g; Sippr-BK Laboratory Animal Co., Ltd.). All mice were fed with standard mouse irradiated food and tap water ad libitum, and maintained under conditions of $25^{\circ} \mathrm{C}$ and $50 \%$ humidity with a 12 -h light/dark cycle. After 3 weeks, the mice were randomly divided into two groups of five, receiving subcutaneous TP $(1.5 \mathrm{mg} / \mathrm{kg}$ ) or saline (mock) injections every day for 5 weeks. The body weight and tumor volume were measured every 2 days. The tumor volume was calculated as (length $\mathrm{x}$ width $\mathrm{x}$ width) $/ 2$. Then, all mice were euthanized using carbon dioxide in according with the Guidelines for Euthanasia of Rodents Using Carbon Dioxide issued by the National Institutes of Health. After euthanasia, death was further verified by cardiac arrest and cadaveric rigidity. The animal experiments were approved by the Animal Experimentation Ethics Committee of the Tongde Hospital of Zhejiang Province.

Terminal deoxynucleotidyl-transferase-mediated dUTP nick end labeling (TUNEL) assay. TUNEL assays were performed to investigate the apoptotic cells in tumor tissues using an in situ cell death detection kit obtained from Roche Diagnostics. Tumor tissue was fixed with a mixture of $70 \%$ alcohol, formaldehyde and glacial acetic acid (16:1:1) at $4^{\circ} \mathrm{C}$ for $24 \mathrm{~h}$, and paraffin-embedded tumor sections $(5-\mu \mathrm{m})$ were 
A
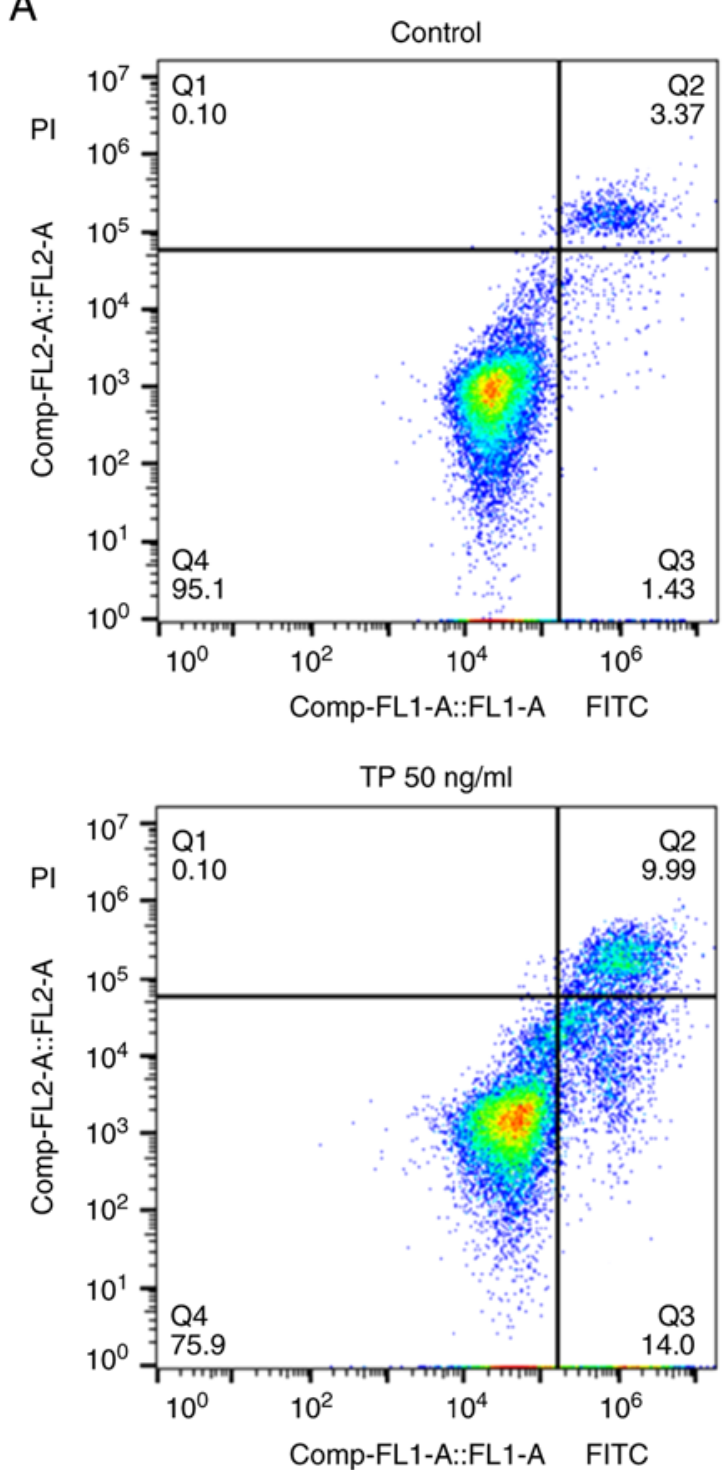
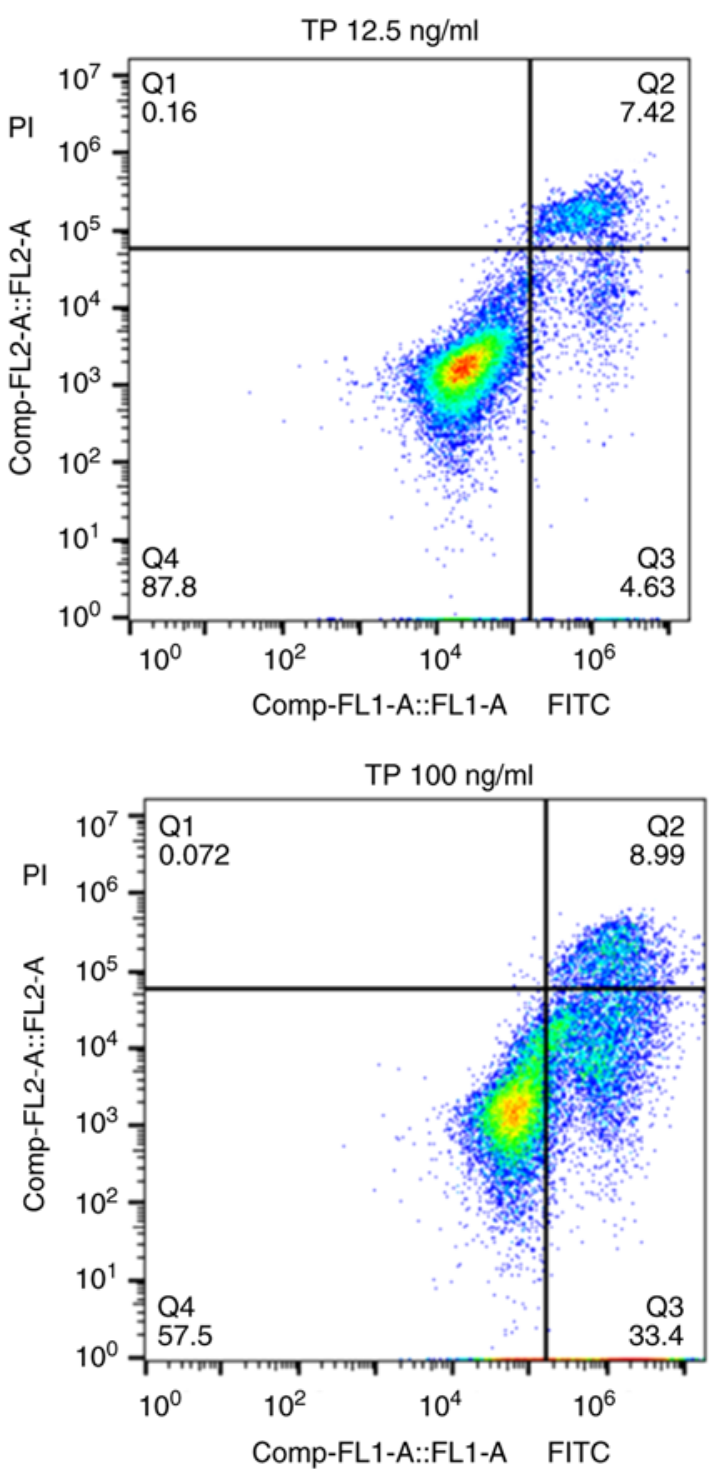

Figure 1. TP inhibits the survival of A549 cells. (A) Flow cytometry analyses of A549 cells treated with various concentrations (12.5, 50 and $100 \mathrm{ng} / \mathrm{ml})$ of TP for $36 \mathrm{~h}$ using double staining with Annexin V and PI.

dewaxed and rehydrated. Proteinase $\mathrm{K}$ was applied at $37^{\circ} \mathrm{C}$ for $25 \mathrm{~min}$. Membranes were dissolved at room temperature for $20 \mathrm{~min}$. Then, TdT and dUTP were mixed at 1:9 and the mixture incubated with tissues at $37^{\circ} \mathrm{C}$ for $2 \mathrm{~h}$. DAPI solution was used to stain nuclei in the dark at room temperature for $10 \mathrm{~min}$. A fluorescence microscope was used to observe and photograph the apoptotic cells. Positive cells were marked by green fluorescence. TUNEL-positive cells and total cells in sections were measured using ImageJ v1.8.0 software.

Immunohistochemistry. The tissue samples $(5 \mu \mathrm{m})$ were deparaffinized and rehydrated. A timer-controlled water bath was used to conduct heat-induced antigen retrieval at $98^{\circ} \mathrm{C}$ for $20 \mathrm{~min}$. TBS plus $0.025 \%$ Triton $\mathrm{X}-100$ was used to wash the slides with gentle agitation. The slides were then blocked with $10 \%$ BSA in TBS at room temperature for $2 \mathrm{~h}$. Primary antibodies against p53 (1:150; cat. no. 2527; Cell Signaling Technology, Inc.), RPL23 (1:50; cat. no. 16086-1-AP; ProteinTech Group, Inc.) and NCL
(1:400; cat. no. 14574; Cell Signaling Technology, Inc.) were incubated with the samples overnight at $4^{\circ} \mathrm{C}$, and $50 \mu 1$ horseradish peroxidase-conjugated secondary antibody (cat. no. 8114S; Cell Signaling Technology, Inc.) was used to recognize the primary antibody at room temperature for $1 \mathrm{~h}$. The tissues were then stained with 3,3'-diaminobenzidine and subsequently hematoxylin at room temperature for $4 \mathrm{~min}$, and the samples were observed under a light microscope (magnification, $\mathrm{x} 40$ ) in 20 fields of vision and quantified by ImageJ v1.8.0 software.

Statistical analyses. Experiments were performed in triplicate at least three times, independently. Data are presented as the mean \pm standard deviation. One-way, two-way or mixed ANOVA followed by Tukey's, Dunnett's or Sidak's multiple comparisons test, or Student's t-test in GraphPad Prism 6 (GraphPad Software, Inc.) were used to analyze the statistical significance between groups. $\mathrm{P}<0.05$ was considered to indicate a statistically significant difference. 
B
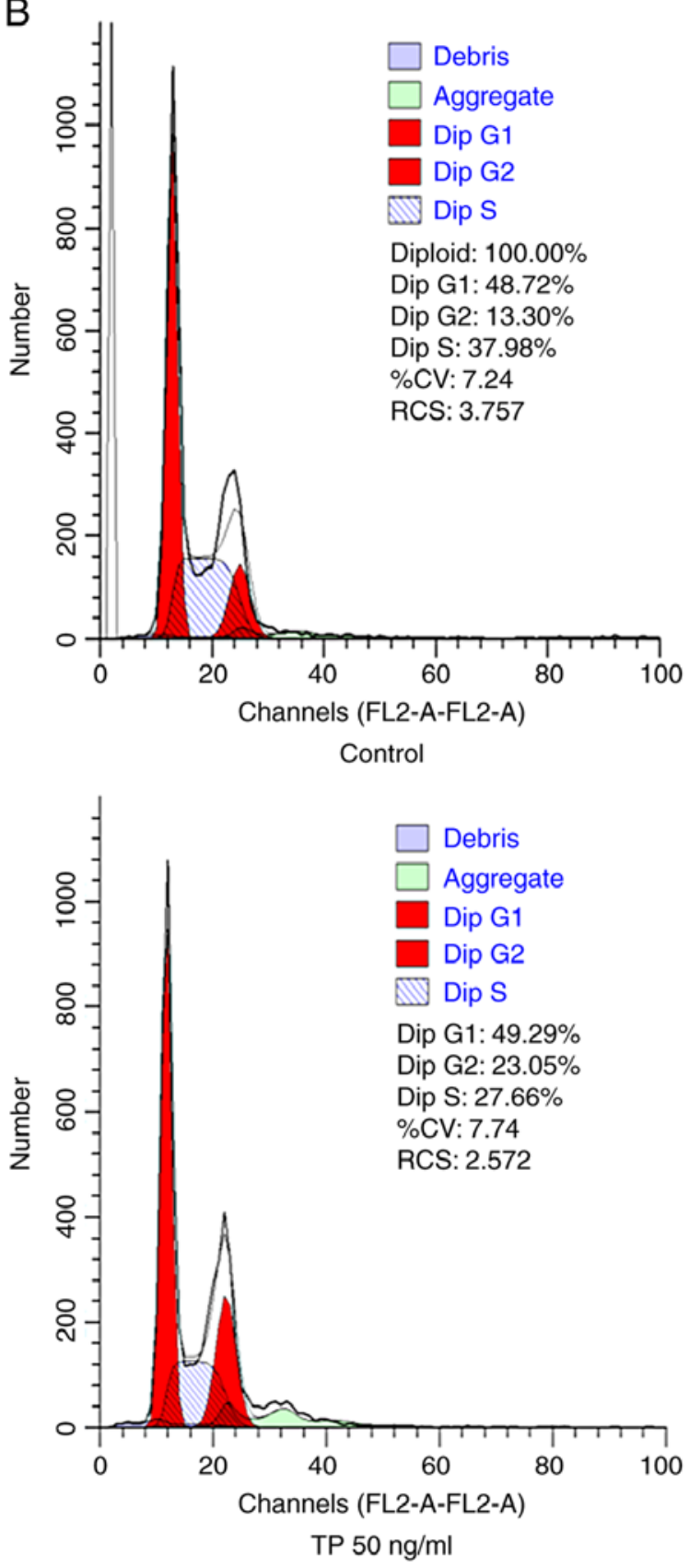
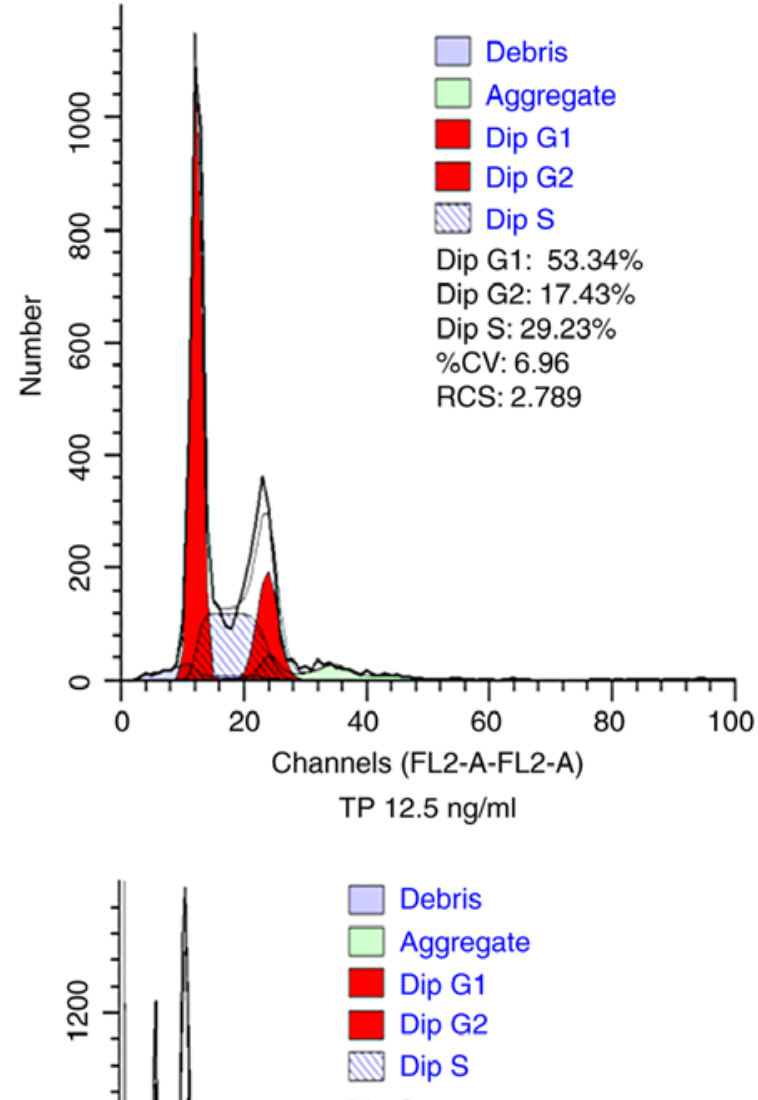

Dip G1: 13.78

Dip G2: $38.03 \%$

Dip S: $48.19 \%$

\%CV: 7.30

RCS: 3.647
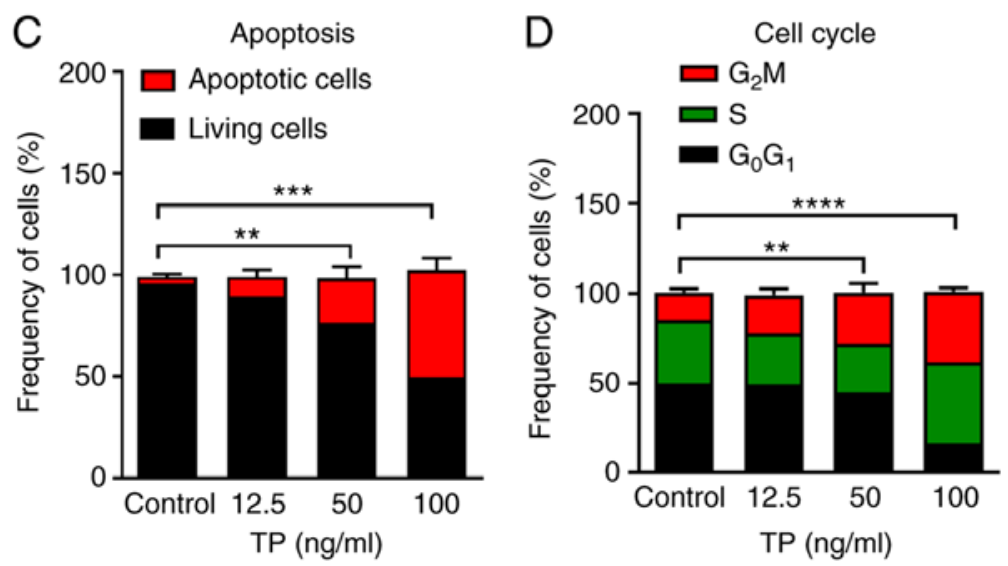

E

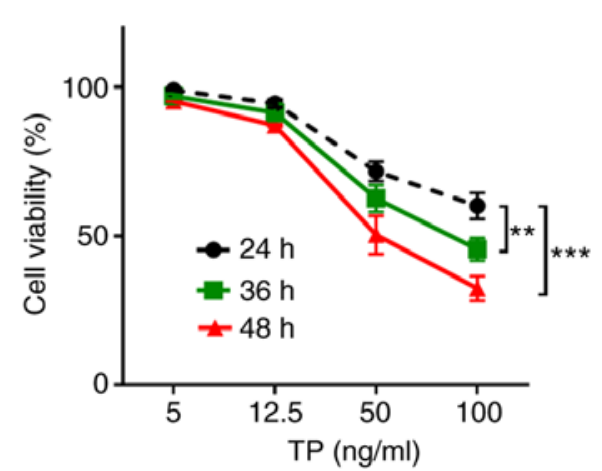

Figure 1. Continued. TP inhibits the survival of A549 cells. (B) A549 cells were treated with the indicated concentrations of TP for 36 h, stained with PI and analyzed via flow cytometry for cell cycle analysis. Quantification of (C) apoptosis and (D) cell cycle analysis. Data are presented as the mean \pm SD of three independent experiments. (E) A549 cells in 96-well plates were treated with the indicated concentrations of TP (12.5, 50 and $100 \mathrm{ng} / \mathrm{ml})$ for 24,36 and $48 \mathrm{~h}$. Cellular growth was measured using a Cell Counting Kit- 8 assay. Data are presented as the mean \pm SD of three independent experiments. Data were analyzed using one- or two-way ANOVA followed by Dunnett's multiple comparisons test. ${ }^{* *} \mathrm{P}<0.01,{ }^{* * *} \mathrm{P}<0.001,{ }^{* * * * *} \mathrm{P}<0.0001$. TP, triptolide; PI, propidium iodide. 
A
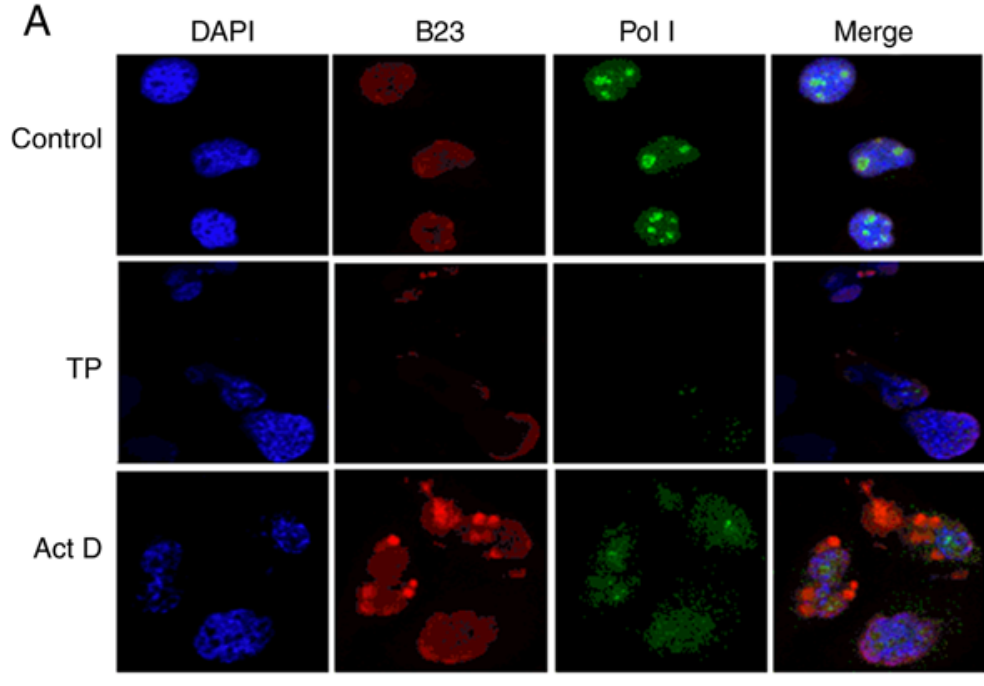

B
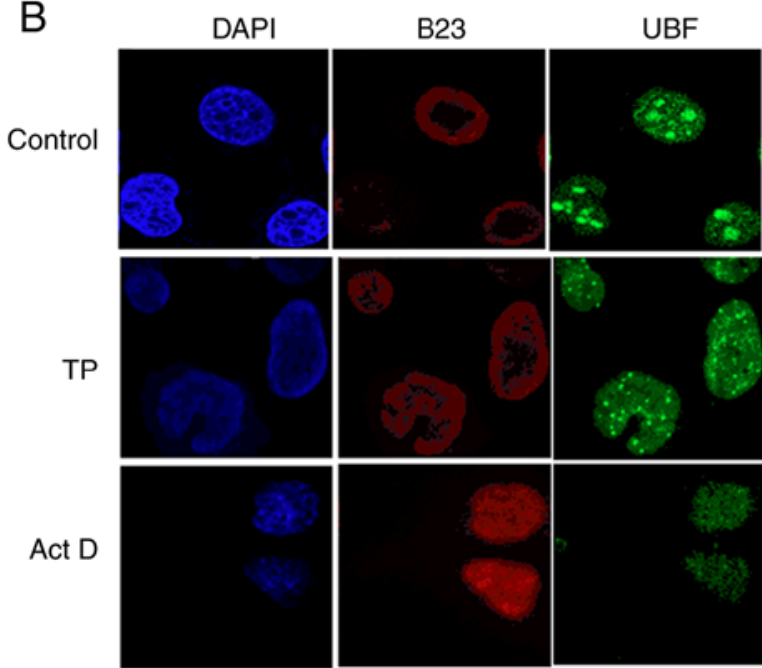

Act D

Figure 2. TP induces nucleolus disintegration and suppresses ribosomal DNA transcription factors. A549 cells $\left(2 \times 10^{4}\right)$ were seeded on coverslips were treated with TP $(50 \mathrm{ng} / \mathrm{ml})$, Act D (20 ng/ml) or DMSO for $24 \mathrm{~h}$, fixed and stained with (A) anti-Pol I or (B) anti-UBF antibodies; B23 was used to stain the nucleoli. Data are presented as the mean \pm SD of three independent experiments. Pictures were captured under a confocal microscope (magnification, $x 63$ ). Data were analyzed using one-way ANOVA combined with Dunnett's multiple comparisons test. ${ }^{*} \mathrm{P}<0.05,{ }^{* * *} \mathrm{P}<0.01,{ }^{* * * *} \mathrm{P}<0.001,{ }^{* * * * *} \mathrm{P}<0.0001$. TP, triptolide; Act $\mathrm{D}$, actinomycin D; B23, nucleophosmin; Pol I, RNA polymerase I; UBF, upstream binding factor.

\section{Results}

TP induces apoptosis and cell cycle arrest in A549 cells. The effects of TP were first determined on A549 cells. An Annexin V/PI staining-based assay with fluorescence-activated cell sorting was performed to analyze the population of apoptotic cells. The results showed that TP increased the apoptotic index in a dose-dependent manner (Fig. 1A). The percentage of apoptotic cells gradually increased with increasing TP concentration, from $4.1 \pm 1.34 \%$ in control cells to $12.3 \pm 1.72$, $26.2 \pm 2.16$ and $45.8 \pm 3.28 \%$ in TP-treated cells (Fig. 1C). Then, PI staining was performed to analyze the cell cycle (Fig. 1B). TP caused the G0/G1 fraction to decrease from $48.6 \pm 3.56 \%$ in control cells to $14.9 \pm 1.22 \%$ in $100 \mathrm{ng} / \mathrm{ml} \mathrm{TP}$-treated cells, and the $\mathrm{G} 2 / \mathrm{M}$ fraction increased from $14.2 \pm 2.42 \%$ in the control to $19.2 \pm 2.68 \%$ (12.5 ng/ml TP), $25.2 \pm 3.11 \%$ (50 $\mathrm{ng} / \mathrm{ml} \mathrm{TP})$ and $38.9 \pm 3.62 \%$ (100 ng/ml TP; Fig. 1D). These results indicated that TP arrested A549 cells at the G2/M phase. Then, the effect of TP on cell viability was evaluated. As presented in
Fig. 1E, TP induced a marked dose-dependent reduction in cell viability; increasing the duration of treatment from $24 \mathrm{~h}$ to $48 \mathrm{~h}$ significantly enhanced this inhibition.

TP induces nucleolar RNA Pol I and UBF translocation and nucleolar disintegration. The expression and distribution of Pol I in the nucleus was investigated. Cells were treated with a negative control, TP, or a positive control, Act D, for $36 \mathrm{~h}$. Act D is a well-characterized nucleolar disruptor (19). The prepared cells were dually stained with antibodies against the RNA Pol I antigen and B23; B23 is associated with ribosome biogenesis and nucleolar ribonucleoproteins (20). As presented in Fig. 2A, endogenous RNA Pol I was present primarily in the nucleolus in the control cells. Treatment with TP and Act $\mathrm{D}$ resulted in abnormal nuclear morphology and nucleolar disintegration, and faint traces of RNA Pol I were observed in TP-treated cells. For UBF, robust protein expression was observed in almost all nucleoli in the negative control cells; TP and Act D induced nucleolar disintegration and further 

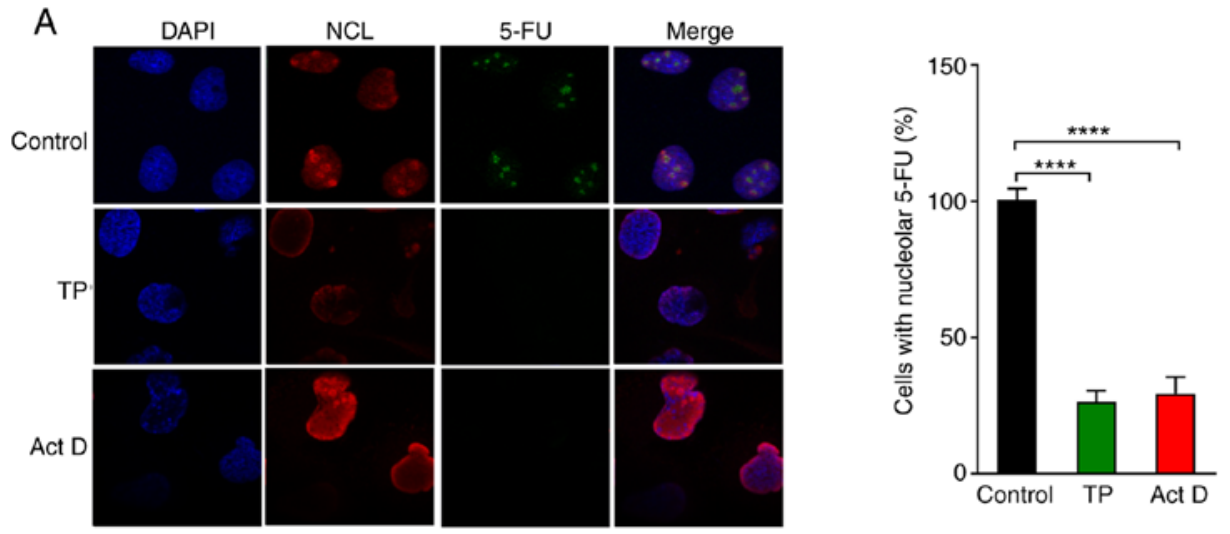

B
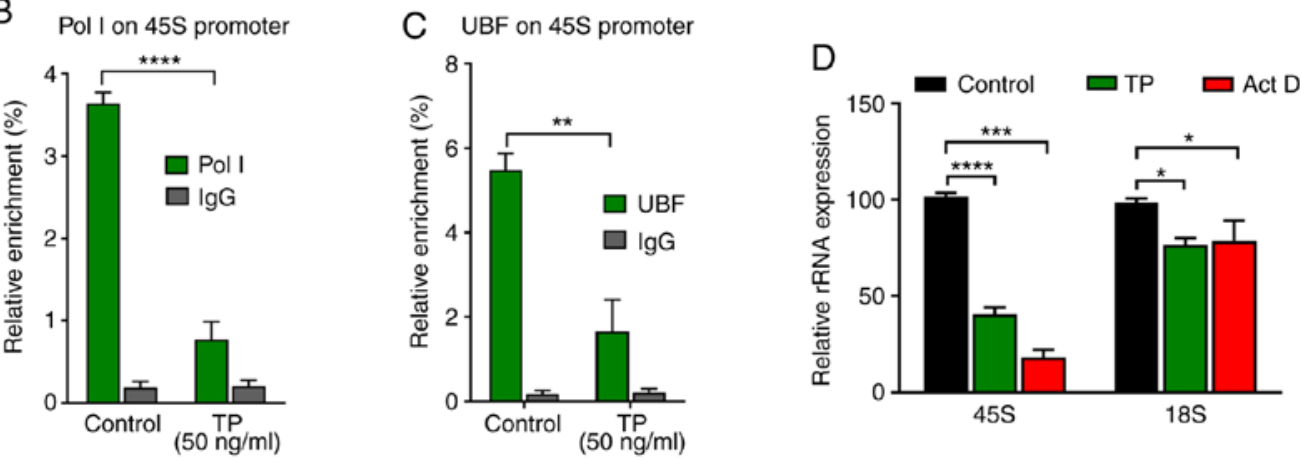

Figure 3. TP reduces rRNA synthesis and suppresses rRNA processing. (A) A549 $\left(2 \times 10^{4}\right)$ cells were seeded on coverslips and first treated with TP (50 ng/ml) or Act D $(20 \mathrm{ng} / \mathrm{ml})$ for $24 \mathrm{~h}$; newly synthesized RNA was labeled with 5-FU for $15 \mathrm{~min}$ before the cells were harvested, and Alexa Fluor-conjugated monoclonal antibodies were used to mark 5-FU-labeled RNA. NCL was used to stain the nucleoli, and DAPI was used to counterstain the nuclei. Images were captured under a confocal microscope (magnification, x63). A549 Cells $\left(1 \times 10^{7}\right)$ treated with TP $(50 \mathrm{ng} / \mathrm{ml}, 24 \mathrm{~h})$ were subjected to chromatin immunoprecipitation assays for (B) Pol I and (C) UBF occupancy of the promoter region of 45S rRNA. (D) Reverse transcription-quantitative PCR analysis was used to evaluate $45 \mathrm{~S}$ and $18 \mathrm{~S}$ expression. Data are presented as the mean $\pm \mathrm{SD}$ of at least three independent experiments, and were analyzed using one-way ANOVA combined with Dunnett's multiple comparisons test or two-way ANOVA combined with Sidak's multiple comparisons test. ${ }^{*} \mathrm{P}<0.05,{ }^{* * *} \mathrm{P}<0.01,{ }^{* * * *} \mathrm{P}<0.001,{ }^{* * * * *} \mathrm{P}<0.0001$. TP, triptolide; Act D, actinomycin D; r, ribosomal; NCL, nucleolin; Pol I, RNA polymerase I; UBF, upstream binding factor; 5-FU, 5-fluorouridine.

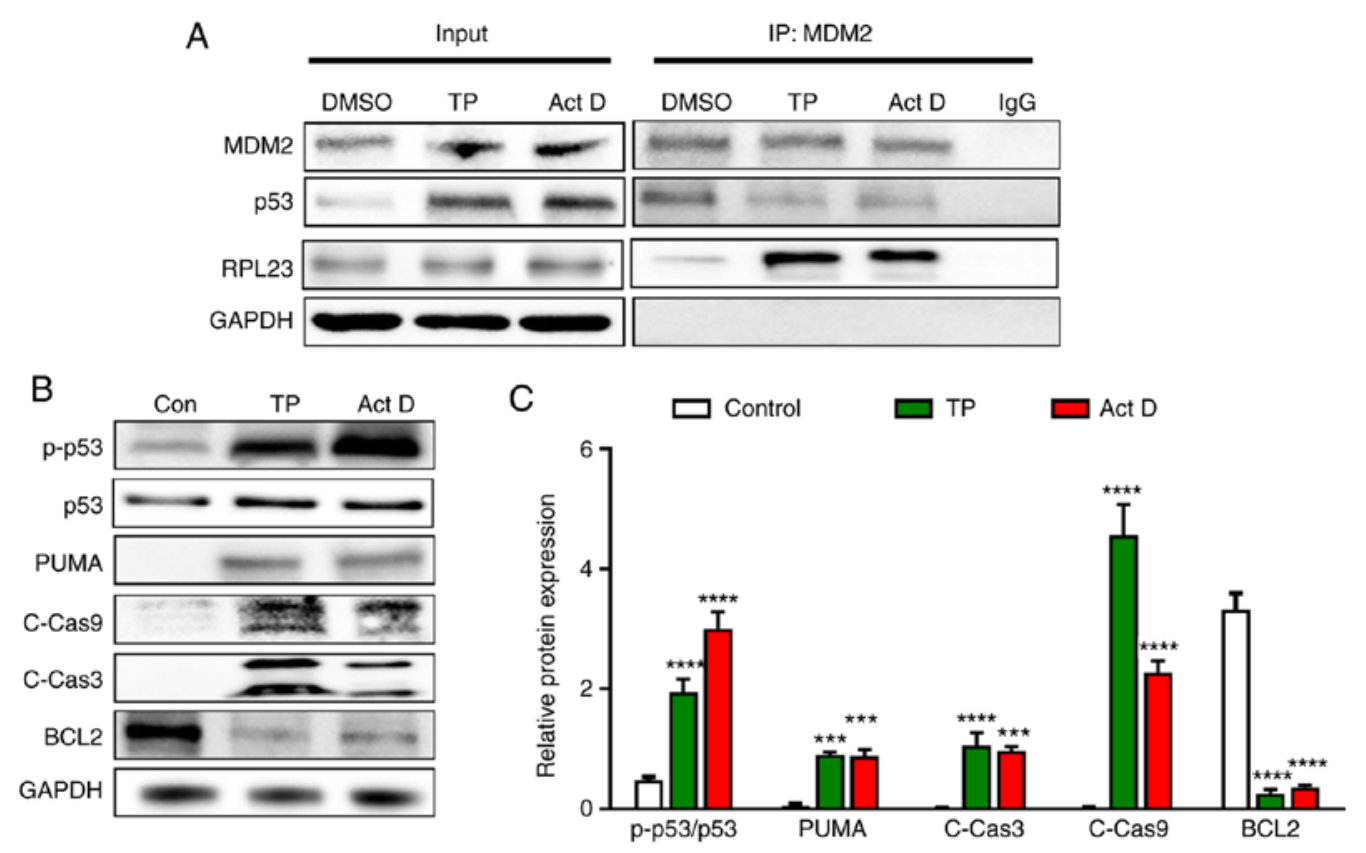

Figure 4. TP increases the binding of RPL23 with MDM2 and activates p53 and p53-regulated proteins. (A) Cell lysates of TP-treated cells $\left(5 \times 10^{6}\right)$ were immunoprecipitated with anti-MDM2 antibodies, followed by immunoblotting with anti-MDM2, p53 and RPL23 antibodies. For each lysate, 20\% of the quantity used for IP was loaded as an input control. (B) Cell lysates from $5 \times 10^{6} \mathrm{~A} 549$ cells receiving various treatments for $48 \mathrm{~h}$ were subjected to western blot analysis with the indicated antibodies; GAPDH was used as an internal control. (C) Densitometric analysis of protein expression. Data are presented as the mean \pm SD of at least three independent experiments. Data were analyzed using one-way ANOVA combined with Tukey's multiple comparisons test. ${ }^{* * * *} \mathrm{P}<0.001,{ }^{* * * * *} \mathrm{P}<0.0001$ vs. control. TP, triptolide; MDM2, mouse double minute 2; RPL23, ribosomal protein L23; PUMA, p53-upregulated modulator of apoptosis, C-Cas, cleaved caspase; p, phosphorylated; IP, immunoprecipitation. 
A

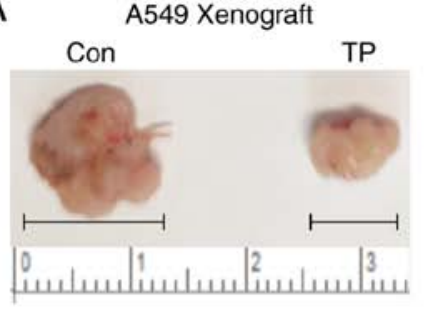

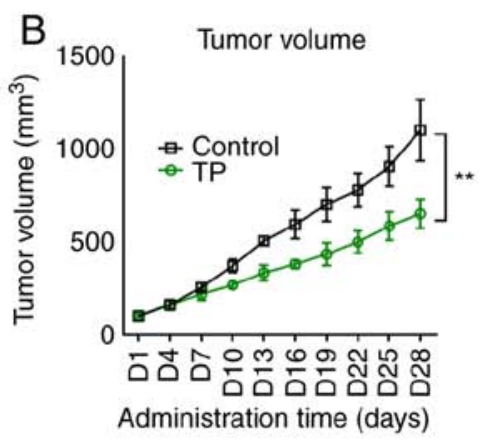

$\operatorname{DAPI}(400 x)$
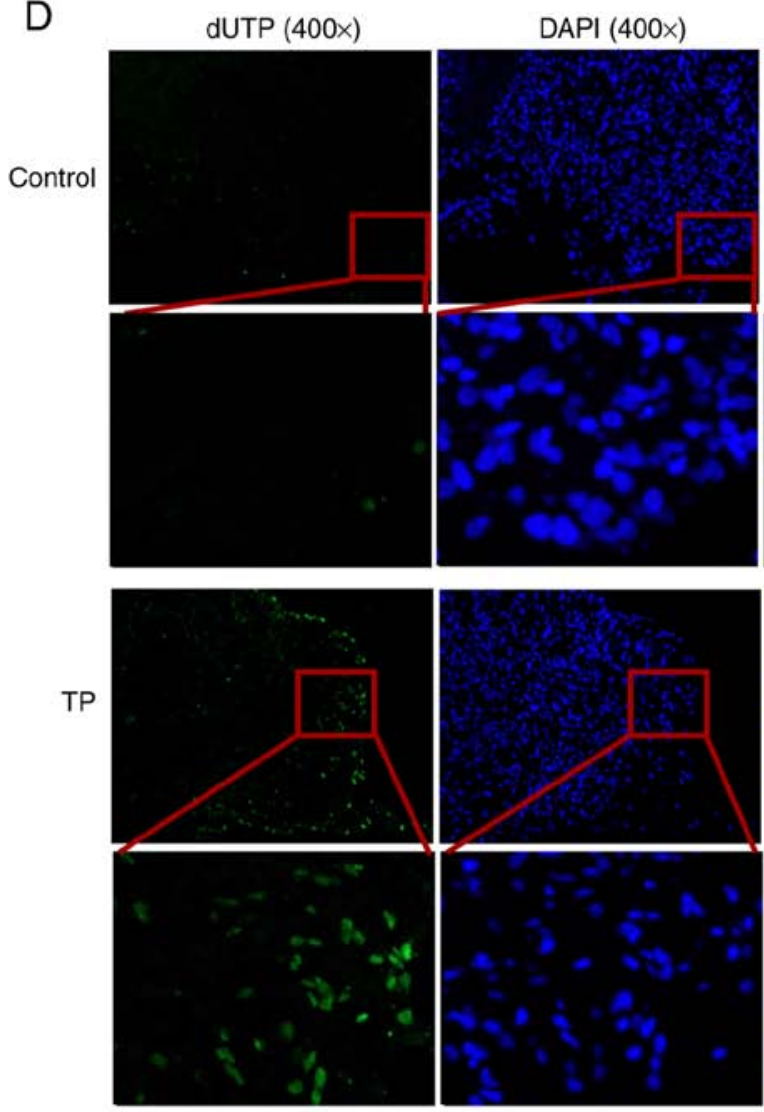
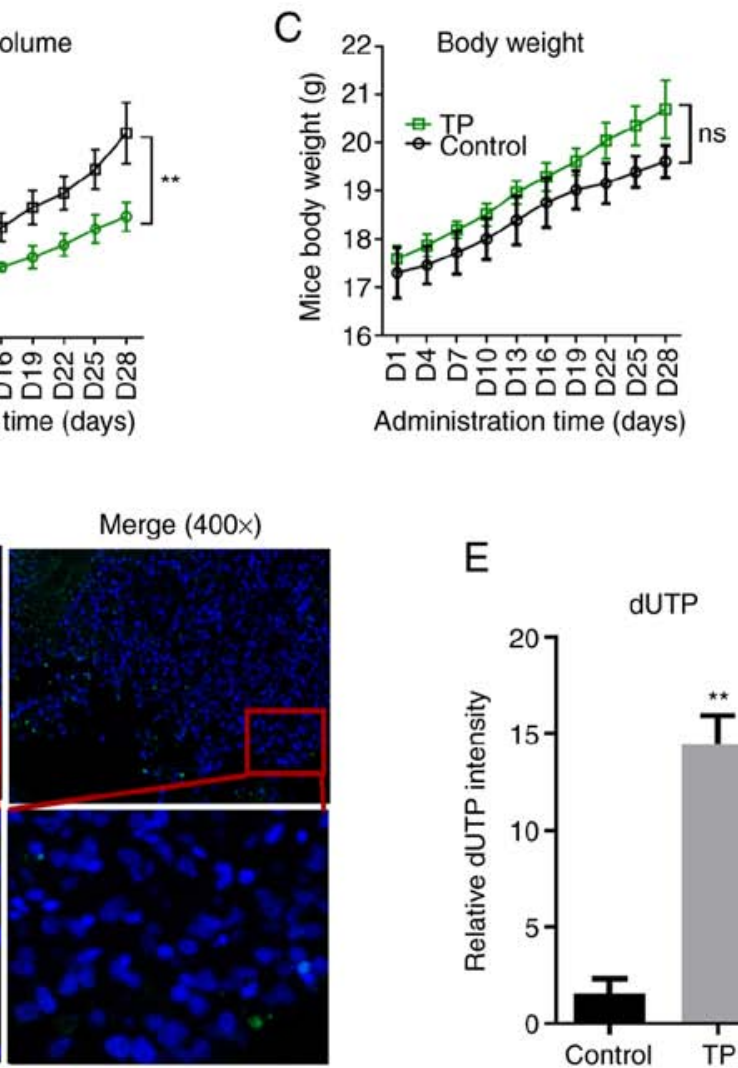

Administration time (days)
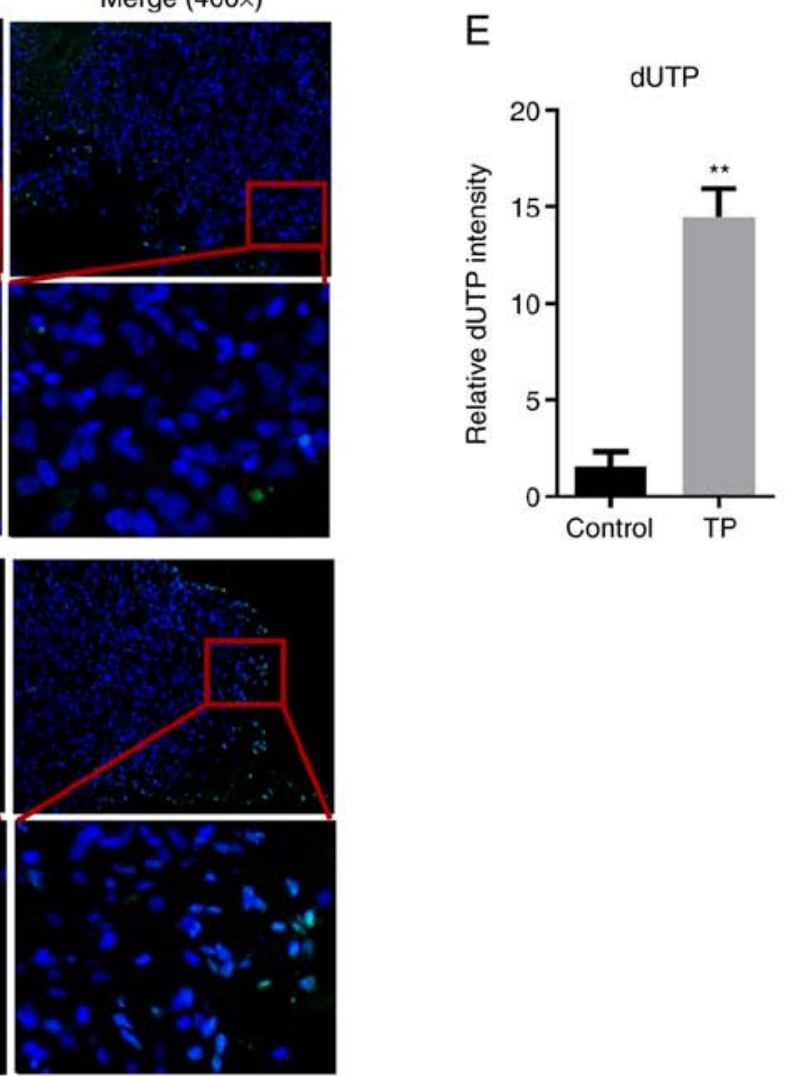

Figure 5. TP inhibits the growth of A549 xenografts in nude mice and induces apoptosis. (A) Representative xenograft tumors from mice treated subcutaneously with TP or saline control. (B) Tumor volume and (C) body weight of control and TP-treated mice were recorded every 2 days. (D) Tumors from the two groups were analyzed using TUNEL assays, and increased dUTP expression indicated apoptotic cells. (E) Quantification of fluorescence intensity. Data are presented as the mean \pm SD. The statistical differences between groups were analyzed using Student's t-test or mixed ANOVA combined with Sidak's multiple comparisons test. ${ }^{* *} \mathrm{P}<0.01$. TP, triptolide.

diffused the distribution of UBF throughout the nucleus rather than being focused in the nucleolus (Fig. 2B). The RNA Pol I and UBF relative fluorescent intensities were significantly reduced in the TP-treated cells.

TP interrupts rRNA synthesis and rRNA processing. Burger et al (21) demonstrated that the disintegration of nucleolar structures is related to rRNA synthesis. Therefore, immunofluorescence assays were performed to detect whether TP plays a role in the process of RNA synthesis. NCL, a multifunctional protein that mainly regulates ribosome biogenesis and transcription, was used as a control to evaluate the integrity of the nucleoli. The results in Fig. 3A revealed that TP treatment significantly reduced the incorporation of
5-FU into nascent rRNA, suggesting that TP treatment inhibited rRNA synthesis. The ChIP assay demonstrated that TP treatment caused significant dissociation of Pol I and UBF from the promoter region of the rDNA in a dose-dependent manner (Fig. 3B and C); these results were consistent with the decreased localization of RNA Pol I and UBF observed in Fig. 2A and B. 45S rRNA is the transcriptional product driven by Pol I and UBF, and maturation of the primary transcript leads to the generation of 18S rRNA (16). RT-qPCR analysis was performed to determine the effect of TP on primary rRNA transcript 45S and modified 18S. The results in Fig. 3D showed that TP significantly reduced the expression of $45 \mathrm{~S}$ pre-rRNA in a dose-dependent manner, and the expression of $18 \mathrm{~S}$ expression was also significantly impaired. This result indicated that 
A

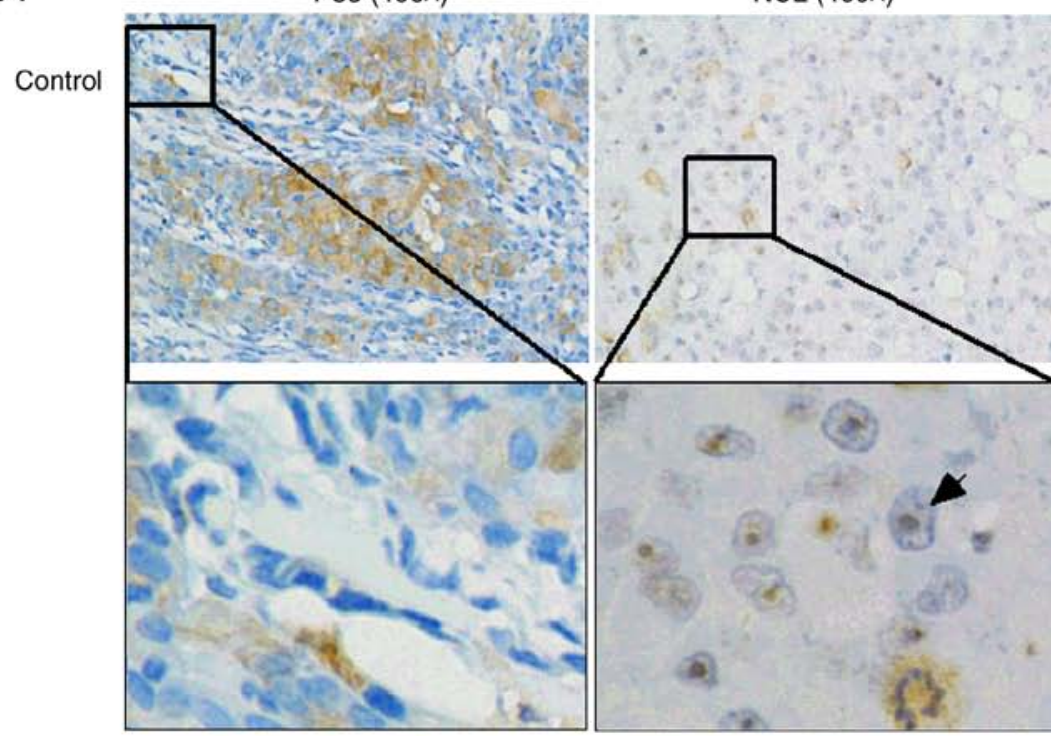

TP

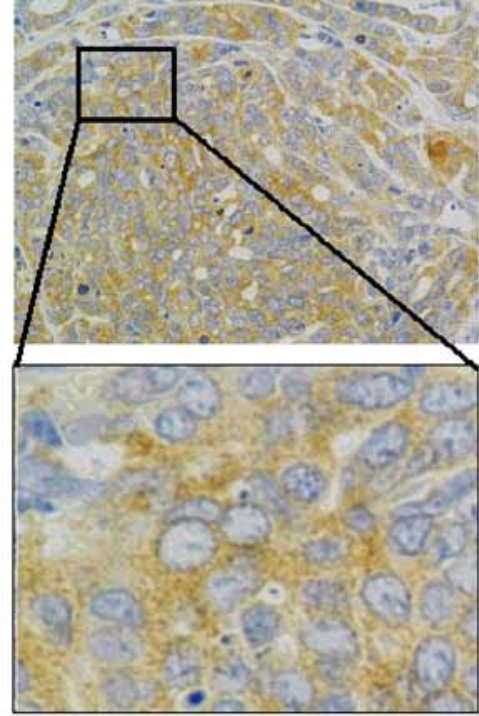

B

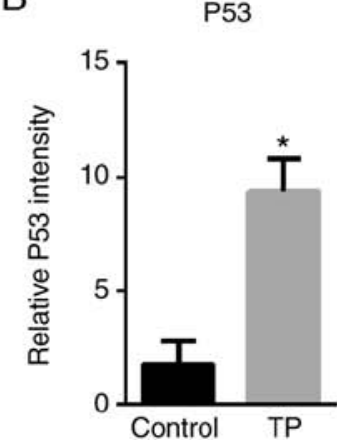

NCL (400x)

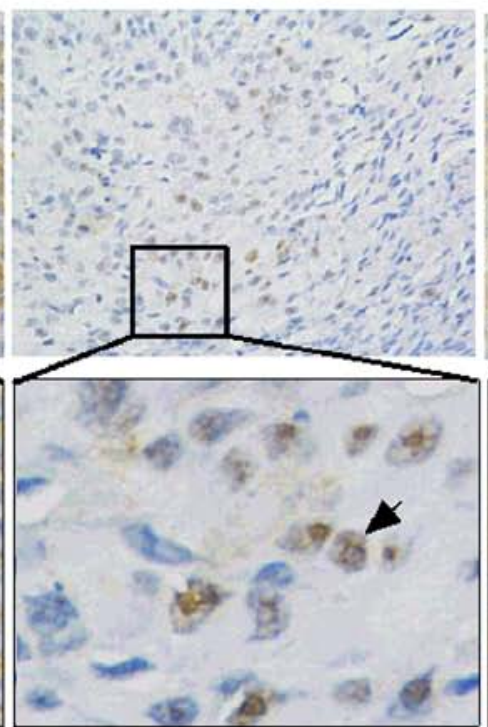

C

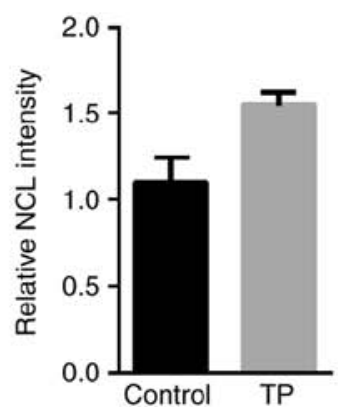

RPL23 (400x)
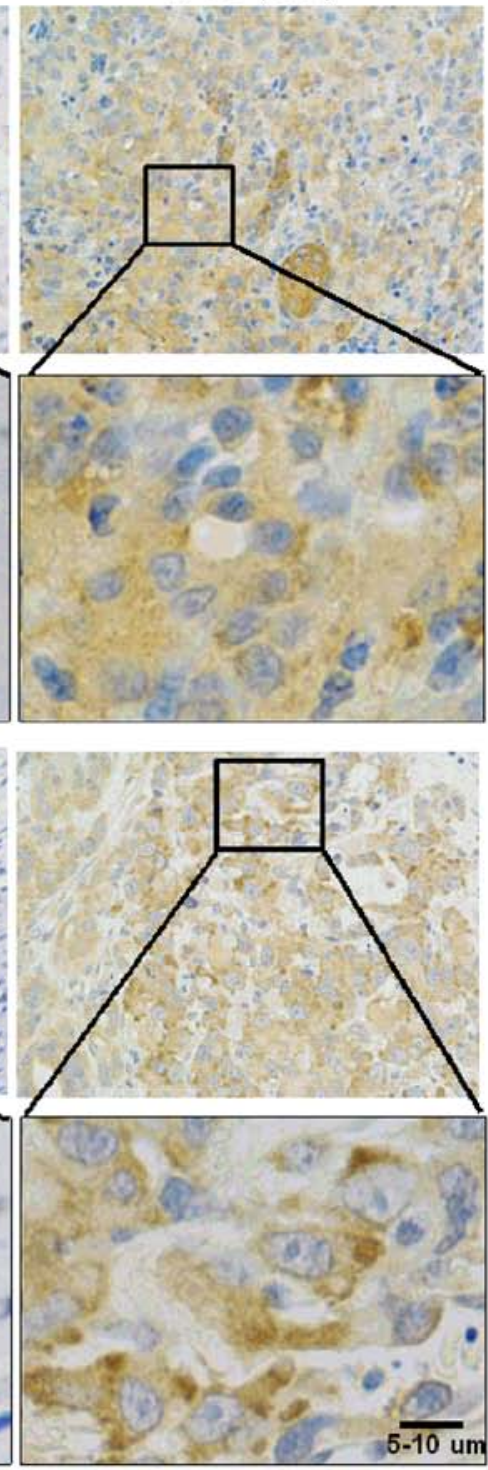

D

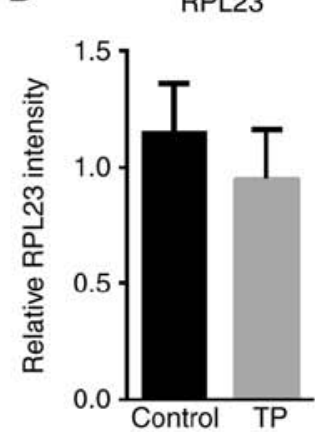

Figure 6. TP induces ribosomal stress in A549 xenografts. (A) Protein levels of p53, NCL and RPL23 in xenografts from control and TP-treated animals as determined via immunohistochemistry. Quantification of the levels of (B) p53, (C) NCL and (D) RPL23. Data are presented as the mean \pm SD. Student's t-test was used to analyze the difference between two groups. ${ }^{*} \mathrm{P}<0.05$. TP, triptolide; NCL, nucleolin; RPL23, ribosomal protein L23.

TP inhibited rRNA synthesis by inhibiting Pol I and UBF, thus further interfering with rRNA processing.

TP induces apoptosis and cell cycle arrest by increasing the binding of RPL23 to MDM2. When ribosome biogenesis is interrupted, RPs may not be used for ribosome biogenesis and can bind to MDM2, which inhibits MDM2 from mediating p53 degradation $(22,23)$. To determine whether there are intrinsic links between TP-induced ribosome biogenesis disorder and cell survival inhibition, A549 cells were treated with TP or a positive control, and co-IP assays were carried out with an anti-MDM2 antibody to pull down the associated 


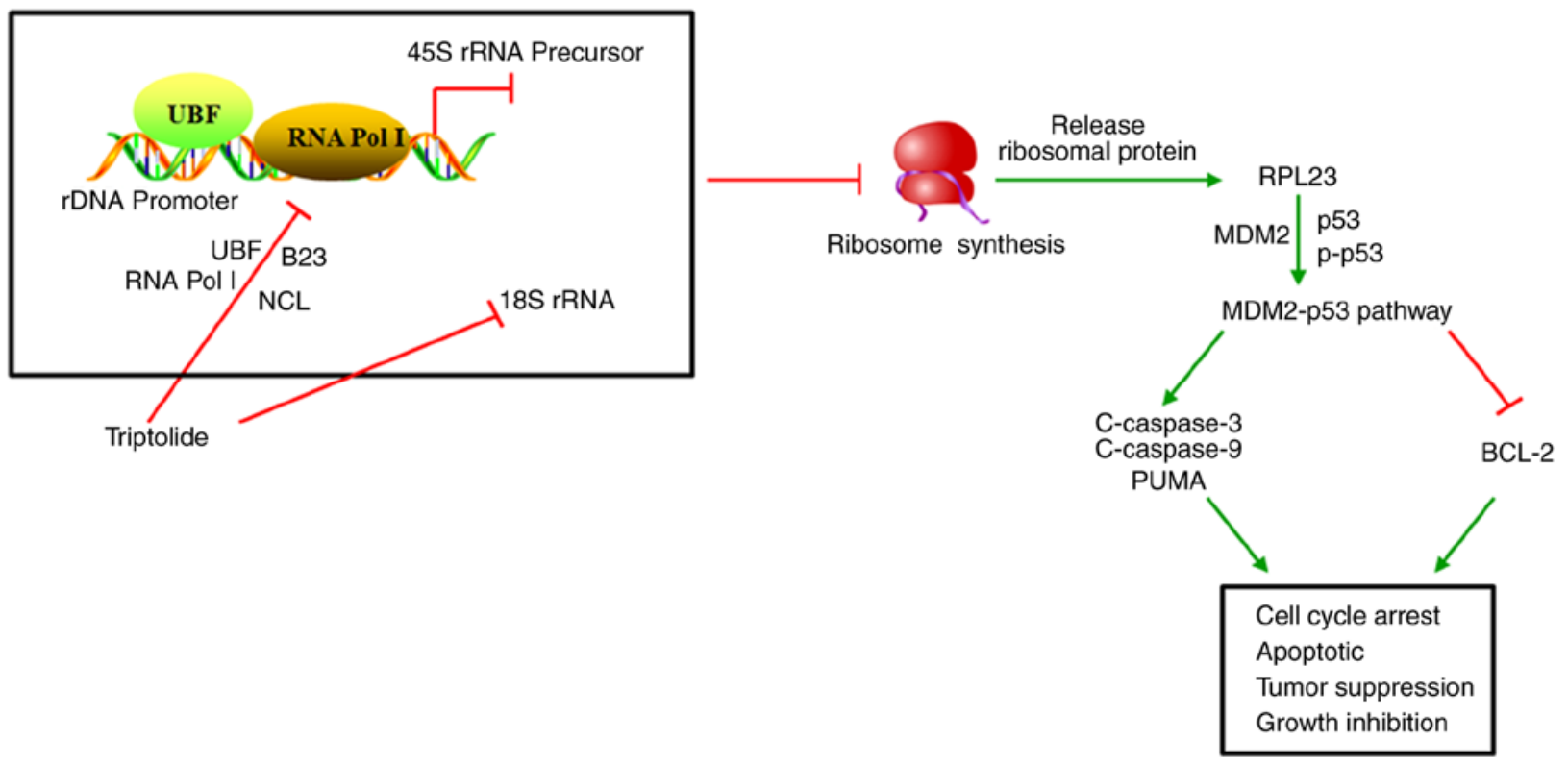

Figure 7. Schematic diagram of the mechanism of TP-induced lung cancer cell inhibition via ribosomal stress initiation. TP induces nucleolus degradation and inhibits 45S rRNA synthesis by reducing the binding of Pol I and UBF to the rDNA promoter. The 18S rRNA degraded by TP disrupts ribosomal synthesis, resulting in the liberation of RPL23. The combination of RPL23 with MDM2 activates p53, which drives apoptosis, growth inhibition and cell cycle arrest. TP, triptolide; Pol I, RNA polymerase I; UBF, upstream binding factor; RPL23, ribosomal protein L23; MDM2, mouse double minute 2; NCL, nucleolin; B23, nucleophosmin; PUMA, p53-upregulated modulator of apoptosis; C, cleaved; p, phosphorylated; r, ribosomal.

proteins. The results showed that TP treatment increased the binding of RPL23 to MDM2 and reduced the binding of p53 to MDM2 (Fig. 4A). These results suggested that there may be competitive binding of RPL23 and p53 to MDM2. The increased binding of RPL23 to MDM2 led to reduced binding of $\mathrm{p} 53$, resulting in decreased MDM2-mediated degradation of $\mathrm{p} 53$.

p53 stabilization can evoke signaling events involved in cell survival, such as apoptotic and cell cycle pathways (24). As shown in Fig. 4B and C, TP treatment induced increases in p-p53, and activation of caspase 9 and caspase 3. Reduced levels of BCL2 were also induced by TP and the positive control. These results suggested that TP induced apoptosis and cell cycle arrest via p53 activation.

TP suppresses tumor growth by inducing ribosomal stress in vivo. To further validate the effects of TP on A549 cell survival, A549 xenografts were implanted in nude mice. $\mathrm{BALB} / \mathrm{c}$ mice were injected subcutaneously on their right limb. At 3 weeks later, the mice were divided randomly into two groups of five mice. Each group was treated with saline or TP once a day for 4 weeks. The results showed that TP treatment notably inhibited tumor growth from day 13 (Fig. 5A and B). Moreover, the body weights of the TP-treated mice were significantly higher than that of the control group (Fig. 5C). TP treatment induced enhanced expression of dUTP, which binds mainly to the terminal 3-OH of fragmented DNA, indicating that apoptosis in TP-treated xenografts was markedly activated (Fig. 5D and E). Consistent with the in vitro experiments, immunohistochemistry revealed robust p53 expression in response to TP administration (Fig. 6A and B). In the control xenografts, NCL was found predominantly in the nucleolus; however, TP treatment caused it to disperse to the nucleus (Fig. 6A), suggesting that the nucleolus was disrupted. NCL and RPL23 exhibited nearly the same expression intensity between the two groups (Fig. 6C and D); however, TP treatment resulted in RPL23 being more likely to be located at the edge of the cell membrane (Fig. 6A).

\section{Discussion}

The nucleolus is a pressure sensor that contains various proteins involved in ribosome synthesis (25). B23, NCL, RNA Pol I and UBF are the main sensory proteins located in the nucleoli (16). In the present study, it was found that B23, NCL, RNA Pol I and UBF were located primarily in the nucleolus in control-treated NSCLC cells, whereas in the TP-treated cells, the nucleolar structure disappeared, and B23, NCL, RNA Pol I and UBF were translocated and dispersed throughout the nucleus. Downregulation of NCL is involved in cell cycle arrest, growth inhibition and apoptosis (26). Inhibition of B23 in atypical teratoid or rhabdoid tumors arrests the cell cycle at G1 phase (27), suggesting that reduced expression and abnormal distribution of NCL and B23 induced by TP are implicated in cell cycle arrest, apoptosis and growth inhibition. These results are consistent with previous findings that ribosomal stress caused by acrolein induced nucleolar disintegration and nucleolus-related molecule translocation (16).

The abnormal distribution and expression of sensory proteins inevitably leads to abnormal ribosomal rRNA synthesis $(28,29)$. rRNA synthesis is the first step of ribosome biogenesis in the nucleolus. RNA Pol I and UBF are essential members of the pre-initiation complex that promotes the initiation of rDNA promoter transcription (30). Disrupting the binding ability of UBF and RNA Pol I to the rDNA promoter decreases rDNA transcription and rRNA synthesis (31). Previous studies have reported that TP is a known inhibitor of RNA polymerase I; 
therefore, it was hypothesized that the inhibition of rRNA synthesis by TP in the present study was a result of suppression of RNA Pol I. It was shown that TP reduced UBF1 expression in the nucleoli and reduced UBF1 binding to rDNA, which exacerbated the decrease in rRNA synthesis. In addition, the TP-mediated reduction in the expression of precursor $45 \mathrm{~S}$ rRNA also significantly reduced the level of $18 \mathrm{~S}$ rRNA, which is a processed product from precursor $45 \mathrm{~S}$ rRNA. 18S rRNA participates in the biogenesis of the 60S ribosome subunit (32), suggesting that $\mathrm{TP}$ is involved in disruption of the $60 \mathrm{~S}$ ribosome subunit. This is consistent with our previous proteomics analysis showing that TP treatment significantly downregulated proteins involved in ribosome processing (11).

Disruption of ribosome biogenesis evokes signaling pathways that lead to cell cycle arrest, cellular senescence or apoptosis (16). The recruitment and binding of RPs to MDM2 increases significantly after ribosome biogenesis is disrupted; therefore, p53 is freed from MDM2 and no longer degraded by MDM2-mediated ubiquitination, leading to p53 activation (33). In the present study, it was found that ribosomal stress induced by TP cascaded via disintegrating the ribosomal structure, inhibiting rRNA biogenesis and freeing RPL23. Consequently, the released RPL23 robustly and competitively combines with MDM2 to cause the dissociation and activation of p53, consistent with previous observations that RPL23 activates p53 in response to ribosomal perturbation (23). Activated p53 further causes cleavage of caspase 9 , which is implicated in the activation of caspase cascades by cleaving and activating caspase 3 (16). In the present study, increased levels of both c-caspase 3 and c-caspase 9 were observed following TP treatment. The increase in $\mathrm{p} 53$ phosphorylation was associated with an increase in PUMA, which is expressed at very low levels under normal conditions $(34,35)$. The increase in PUMA levels further promoted cellular apoptosis via feedback interactions with p53 (36). In addition, the reduction in BCL2 levels suggested that the apoptosis induced by TP is mitochondria-dependent, consistent with a previous report that TP treatment activated the mitochondrial apoptosis pathway (10).

Disturbances in ribosome synthesis can lead to cell cycle arrest through the retinoblastoma protein pathway and p53-dependent pathway $(37,38)$. In the present study, it was found that TP induced disturbances in ribosome synthesis, suggesting that cell cycle arrest in lung cancer cells induced by TP could be attributed, at least in part, to disturbances in ribosome synthesis. Protein synthesis by ribosomes is a major metabolic event that regulates proliferation and cellular growth. TP-induced inhibition of rRNA synthesis may result in abnormal lung cancer cell proliferation, consistent with reports that ribosome heterogeneity impairs global protein synthesis and normal growth (39). The MDM2-p53 axis is a key signaling pathway that regulates the tumor cell cycle, proliferation and apoptosis (40). Downregulation of MDM2 and p53 ubiquitination promotes the proliferation and cisplatin chemoresistance of cancer cells (41). Zhou et al (42) reported that activating the RPL40-MDM2-p53 pathway induced cell cycle arrest and apoptosis. In the present study, it was found that TP inhibited cell cycle, induced apoptosis and activated the p53-MDM2 pathway, indicating that the inhibitory effect of TP on lung cancer cells may be related to the activation of the $\mathrm{p} 53-\mathrm{MDM} 2$ pathway.
Numerous studies have reported that ribosome synthesis disorder induces the suppression of cancers $(22,43)$. TP has also been shown to markedly induce lung cancer cell apoptosis via multiple mechanisms $(8,10)$; however, the mechanism by which TP inhibits lung cancer by inducing disordered ribosomes has not been reported. The present findings are the first, to our knowledge, to show that TP induced apoptosis, cell cycle arrest, and suppression of cell proliferation and tumor growth via nucleolar disintegration and rRNA synthesis inhibition, potentially via the ribosome-RPL23-MDM2-p53 signaling pathway (Fig. 7). Additional research into the mechanisms of TP's effects on ribosomal biosynthesis is required; however, these results could lead to the development of anticancer therapeutic strategies involving the use of TP.

\section{Acknowledgements}

Not applicable.

\section{Funding}

This work was supported by grants from the National Natural Science Foundation of China (grant no. 81774026) and the Natural Science Foundation of Zhejiang Province (grant nos. LQ19H100002 and Q17H290005).

\section{Availability of data and materials}

The datasets used and/or analyzed during the current study are available from the corresponding author on reasonable request.

\section{Authors' contributions}

WW and JW designed the research. JW, ZQZ, FQL, JNC, XG, and $\mathrm{BBC}$ performed the experiments. JW and ZZQ analyzed the data. JW and ZQZ wrote the manuscript. All authors read and approved the final manuscript.

\section{Ethics approval and consent to participate}

The study was approved by the Animal Experimentation Ethics Committee of the Tongde Hospital of Zhejiang Province, and was performed in accordance with the approved guidelines.

\section{Patient consent for publication}

Not applicable.

\section{Competing interests}

The authors declare that they have no competing interests.

\section{References}

1. Osmani L, Askin F, Gabrielson E and Li QK: Current WHO guidelines and the critical role of immunohistochemical markers in the subclassification of non-small cell lung carcinoma (NSCLC): Moving from targeted therapy to immunotherapy. Semin Cancer Biol 52: 103-109, 2018. 
2. Jain NA and Otterson GA: Immunotherapy in inoperable stage III non-small cell lung cancer: A review. Drugs Context 8: 212578, 2019.

3. Zhang D, Jin Q, Jiang C, Gao M, Ni Y and Zhang J: Imaging cell death: Focus on early evaluation of tumor response to therapy. Bioconjug Chem Mar 23, 2020 (Epub ahead of print).

4. Li-Weber M: Targeting apoptosis pathways in cancer by Chinese medicine. Cancer Lett 332: 304-312, 2013.

5. de Almeida EM, Ferreira HJ, Alves DR and Da Silva WMB Therapeutic potential of medicinal plants indicated by the Brazilian public health system in treating the collateral effects induced by chemotherapy, radiotherapy, and chemoradiotherapy: A systematic review. Complement Ther Med 49: 102293, 2020.

6. Luo D, Zuo Z, Zhao H, Tan Y and Xiao C: Immunoregulatory effects of Tripterygium wilfordii Hook $F$ and its extracts in clinical practice. Front Med 13: 556-563, 2019.

7. Noel P, Von Hoff DD, Saluja AK, Velagapudi M, Borazanci E and Han H: Triptolide and its derivatives as cancer therapies. Trends Pharmacol Sci 40: 327-341, 2019.

8. Chen SR, Dai Y, Zhao J, Lin L, Wang Y and Wang Y: A mechanistic overview of triptolide and celastrol, natural products from tripterygium wilfordii Hook F. Front Pharmacol 9: 104, 2018.

9. Yan P and Sun X: Triptolide: A new star for treating human malignancies. J Cancer Res Ther 14: S271-S275, 2018.

10. Meng G, Wang W, Chai K, Yang S, Li F and Jiang K: Combination treatment with triptolide and hydroxycamptothecin synergistically enhances apoptosis in A549 lung adenocarcinoma cells through PP2A-regulated ERK, p38 MAPKs and Akt signaling pathways. Int J Oncol 46: 1007-1017, 2015.

11. Li F, Zhao D, Yang S, Wang J, Liu Q, Jin X and Wang W: ITRAQ-based proteomics analysis of triptolide on human A549 lung adenocarcinoma cells. Cell Physiol Biochem 45: 917-934, 2018.

12. Goodfellow SJ and Zomerdijk JC: Basic mechanisms in RNA polymerase I transcription of the ribosomal RNA genes. Subcell Biochem 61: 211-236, 2013.

13. Wang M and Pestov DG: Quantitative northern blot analysis of mammalian rRNA processing. Methods Mol Biol 1455: 147-157, 2016.

14. Russell J and Zomerdijk JC: The RNA polymerase I transcription machinery. Biochem Soc Symp 73: 203-216, 2006.

15. O'Sullivan AC, Sullivan GJ and McStay B: UBF binding in vivo is not restricted to regulatory sequences within the vertebrate ribosomal DNA repeat. Mol Cell Biol 22: 657-668, 2002.

16. Wang HT, Chen TY, Weng CW, Yang CH and Tang MS: Acrolein preferentially damages nucleolus eliciting ribosomal stress and apoptosis in human cancer cells. Oncotarget 7: 80450-80464, 2016.

17. Vispé S, DeVries L, Créancier L, Besse J, Bréand S, Hobson DJ, Svejstrup JQ, Annereau JP, Cussac D, Dumontet C, et al: Triptolide is an inhibitor of RNA polymerase I and II-dependent transcription leading predominantly to down-regulation of short-lived mRNA. Mol Cancer Ther 8: 2780-2790, 2009.

18. Livak KJ and Schmittgen TD: Analysis of relative gene expression data using real-time quantitative PCR and the 2(-Delta Delta C(T)) method. Methods 25: 402-408, 2001.

19. Boulon S, Westman BJ, Hutten S, Boisvert FM and Lamond AI The nucleolus under stress. Mol Cell 40: 216-227, 2010.

20. Mitrea DM, Cika JA, Guy CS, Ban D, Banerjee PR, Stanley CB, Nourse A, Deniz AA and Kriwacki RW: Nucleophosmin integrates within the nucleolus via multi-modal interactions with proteins displaying R-rich linear motifs and rRNA. Elife 5: e13571, 2016.

21. Burger K, Mühl B, Harasim T, Rohrmoser M, Malamoussi A, Orban M, Kellner M, Gruber-Eber A, Kremmer E, Hölzel M and Eick D: Chemotherapeutic drugs inhibit ribosome biogenesis at various levels. J Biol Chem 285: 12416-12425, 2010.

22. Turi Z, Lacey M, Mistrik M and Moudry P: Impaired ribosome biogenesis: Mechanisms and relevance to cancer and aging. Aging (Albany NY) 11: 2512-2540, 2019.

23. Dai MS, Zeng SX, Jin Y, Sun XX, David L and Lu H: Ribosomal protein L23 activates p53 by inhibiting MDM2 function in response to ribosomal perturbation but not to translation inhibition. Mol Cell Biol 24: 7654-7668, 2004.

24. Chen J: The cell-cycle arrest and apoptotic functions of p53 in tumor initiation and progression. Cold Spring Harb Perspect Med 6: a026104, 2016.

25. Deregowska A, Adamczyk J, Kwiatkowska A, Gurgul A, Skoneczny M, Skoneczna A, Szmatola T, Jasielczuk I, Magda M, Rawska E, et al: Shifts in rDNA levels act as a genome buffer promoting chromosome homeostasis. Cell Cycle 14: 3475-3487, 2015.
26. Wang W, Luo J, Xiang F, Liu X, Jiang M, Liao L and Hu J: Nucleolin down-regulation is involved in ADP-induced cell cycle arrest in $\mathrm{S}$ phase and cell apoptosis in vascular endothelial cells. PLoS One 9: e110101, 2014.

27. Phi JH, Sun CH, Lee SH, Lee S, Park I, Choi SA, Park SH, Lee JY, Wang KC, Kim SK, et al: NPM1 as a potential therapeutic target for atypical teratoid/rhabdoid tumors. BMC Cancer 19: 848, 2019.

28. Okur MN, Lee JH, Osmani W, Kimura R, Demarest TG, Croteau DL and Bohr VA: Cockayne syndrome group A and B proteins function in rRNA transcription through nucleolin regulation. Nucleic Acids Res 48: 2473-2485, 2020.

29. Murano K, Okuwaki M, Hisaoka M and Nagata K: Transcription regulation of the rRNA gene by a multifunctional nucleolar protein, B23/nucleophosmin, through its histone chaperone activity. Mol Cell Biol 28: 3114-3126, 2008.

30. Engel C, Gubbey T, Neyer S, Sainsbury S, Oberthuer C, Baejen C, Bernecky $\mathrm{C}$ and Cramer P: Structural basis of RNA polymerase I transcription initiation. Cell 169: 120-131.e22, 2017.

31. Lin YM, Chu PH and Ouyang P: Ectopically expressed pNO40 suppresses ribosomal RNA synthesis by inhibiting UBF-dependent transcription activation. Biochem Biophys Res Commun 516: 381-387, 2019.

32. Sugiyama T, Li S, Kato M, Ikeuchi K, Ichimura A, Matsuo Y and Inada T: Sequential ubiquitination of ribosomal protein uS3 triggers the degradation of non-functional 18S rRNA. Cell Rep 26: 3400-3415.e7, 2019.

33. Zhang Y and Lu H: Signaling to p53: Ribosomal proteins find their way. Cancer Cell 16: 369-377, 2009.

34. Li XQ, Yu Q, Chen FS, Tan WF, Zhang ZL and Ma H: Inhibiting aberrant p53-PUMA feedback loop activation attenuates ischaemia reperfusion-induced neuroapoptosis and neuroinflammation in rats by downregulating caspase 3 and the NF- $\mathrm{BB}$ cytokine pathway. J Neuroinflammation 15: 250, 2018.

35. Garufi A, Pistritto G, Baldari S, Toietta G, Cirone $M$ and D'Orazi G: p53-Dependent PUMA to DRAM antagonistic interplay as a key molecular switch in cell-fate decision in normal/high glucose conditions. J Exp Clin Cancer Res 36: 126, 2017.

36. Chen D, Ni HM, Wang L, Ma X, Yu J, Ding WX and Zhang L: p53 up-regulated modulator of apoptosis induction mediates acetaminophen-induced necrosis and liver injury in mice. Hepatology 69: 2164-2179, 2019.

37. Lessard F, Igelmann S, Trahan C, Huot G, Saint-Germain E, Mignacca L, Del Toro N, Lopes-Paciencia S, Le Calvé B, Montero M, et al: Senescence-associated ribosome biogenesis defects contributes to cell cycle arrest through the Rb pathway. Nat Cell Biol 20: 789-799, 2018.

38. Del Toro N, Fernandez-Ruiz A, Mignacca L, Kalegari P, Rowell MC, Igelmann S, Saint-Germain E, Benfdil M, Lopes-Paciencia S, Brakier-Gingras L, et al: Ribosomal protein RPL22eL22 regulates the cell cycle by acting as an inhibitor of the CDK4-cyclin D complex. Cell Cycle 18: 759-770, 2019.

39. Heissenberger C, Liendl L, Nagelreiter F, Gonskikh Y, Yang G, Stelzer EM, Krammer TL, Micutkova L, Vogt S, Kreil DP, et al: Loss of the ribosomal RNA methyltransferase NSUN5 impairs global protein synthesis and normal growth. Nucleic Acids Res 47: 11807-11825, 2019.

40. Liu X, Tan Y, Zhang C, Zhang Y, Zhang L, Ren P, Deng H, Luo J, Ke Y and Du X: NAT10 regulates p53 activation through acetylating p53 at K120 and ubiquitinating Mdm2. EMBO Rep 17: 349-366, 2016.

41. Xing Y, Liu Y, Liu T, Meng Q, Lu H, Liu W, Hu J, Li C, Cao M, Yan S, et al: TNFAIP8 promotes the proliferation and cisplatin chemoresistance of non-small cell lung cancer through MDM2p53 pathway. Cell Commun Signal 16: 43, 2018.

42. Zhou Q, Hou Z, Zuo S, Zhou X, Feng Y, Sun Y and Yuan X: LUCAT1 promotes colorectal cancer tumorigenesis by targeting the ribosomal protein L40-MDM2-p53 pathway through binding with UBA52. Cancer Sci 110: 1194-1207, 2019.

43. Lempiäinen $\mathrm{H}$ and Shore D: Growth control and ribosome biogenesis. Curr Opin Cell Biol 21: 855-863, 2009.

This work is licensed under a Creative Commons Attribution-NonCommercial-NoDerivatives 4.0 International (CC BY-NC-ND 4.0) License. 